\title{
Investigation of Different Laboratory Aging Methods of Bituminous Mixtures
}

\author{
Cagla Durmaz ${ }^{1}$, Burak Sengoz ${ }^{2 \star}$, Derya Kaya Ozdemir ${ }^{2}$, Ali Topal $^{2}$ \\ ${ }^{1}$ Dokuz Eylul University Graduate School of Natural and Applied Sciences, Buca, 35160 Izmir, Turkey \\ ${ }^{2}$ Department of Civil Engineering, Faculty of Engineering, Dokuz Eylul University, Buca, 35160 Izmir, Turkey \\ * Corresponding author, e-mail: burak.sengoz@deu.edu.tr
}

Received: 25 December 2019, Accepted: 19 January 2021, Published online: 22 January 2021

\begin{abstract}
The predicted performance and service life of the pavement depend largely on the properties of bitumen used in the mixtures. The most important feature of bitumen, which has profound effect on the performance of the road is durability. The durability of bitumen is expressed as the resistance to aging. In this study, the bituminous mixture aging was performed instead of bitumen aging in order to represent the aging in the field in the best possible way. The aim of this paper is to evaluate different proposed laboratory aging methods (NCHRP 09-52, NCHRP 09-54 and RILEM) in relation with the current Standard AASHTO R30 (Standard Practice For Mixture Conditioning of Hot Mix Asphalt standard) and to make comparison with the samples performance taken from the field in terms of Indirect Tensile Strength (ITS). The level of aging has also been compared with the samples taken from recently constructed pavement surface and from the five years old pavement surface. Results depicted that, laboratory aging methods revealed the field aging properties on the unaged bitumen. Based on the results, 2 hours forced draft oven aging at $135^{\circ} \mathrm{C}$ is recommended as short term aging condition because, 2 hours or 4 hours short term forced draft oven aging did not yield significant variation in terms of ITS values. Additionally, 120 hours ( 5 days) oven aging of compacted samples at $85^{\circ} \mathrm{C}$ can be recommended as long term aging condition.
\end{abstract}

\section{Keywords}

aging, oxidation, short term aging, long term aging, hot mix asphalt

\section{Introduction}

Asphalt has been used as a paving material in Europe since the 1850 s and the hardening or stiffening of asphalt has been investigated since around 1900 in the United States $[1,2]$. Keeping the aging occurrence under control is crucial for asphalt samples because it affects the rheological, morphological, and microstructural properties of the sample [3-5]. Traxler [6] listed 5 factors affecting the aging of asphalt in order of importance:

1. Oxidation

2. Volatilization

3. Time

4. Polymerization

5. Condensation

Traxler [7] increased the above factors to 15 in 1963. Four of these 15 items were believed to contribute most to hardening. In 1984, Petersen [8] reduced them to three major factors regarding the aging of asphalt mixtures:

1. Loss of the oily components of bitumen by volatility or absorption by porous volatilization
2. Changes in the chemical composition of bitumen molecules from reaction with atmospheric oxygenoxidation

3. Molecular structuring that produces thixotropic effects-steric hardening

Later, most of the researchers carried out studies based on these three factors.

There are two components of aging to consider [9]:

1. Short term aging (STA)

2. Long term aging (LTA)

Short-term aging occurs during storage of the mixture, mixing in plant, transporting to construction site, laying and compaction. This is probably thought to be caused by volatilization. Long-term aging, which is thought to be predominantly caused by oxidation, occurs during its service life and while exposed to the environment [9].

Fig. 1 shows the aging index values depending on the years of bitumen. It is seen that, approximately $70 \%$ of oxidation occurs during short term aging period. Oxidation 


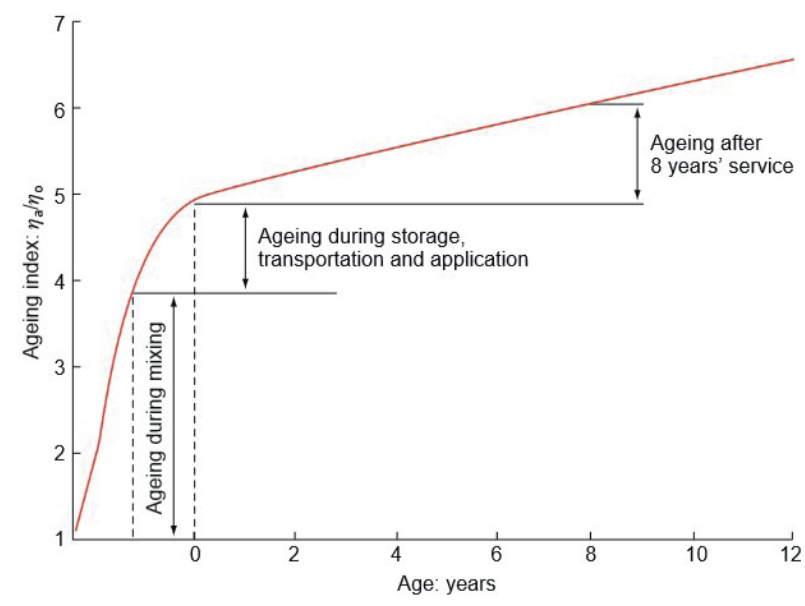

Fig. 1 Aging of asphalt during mixing, subsequently during storage, transportation, and in service [10]

decelerates during the long term aging period and is only around $30 \%$ in 8 years. As can be seen from the figure, rapid aging occurs during the preparation, laying and compaction of the mixture, which slows down at low temperatures during service life of the road.

\section{Previous studies on asphalt-aggregate aging}

There have been several research studies conducted to developed laboratory aging procedures of asphalt mixtures. These studies have identified many interrelated factors such as; source of bitumen, bitumen type, absorption, production temperature and silo storage time etc. $[11,12]$

The results of their studies have depicted that, laboratory aging procedures brought in similar properties to the bitumen with the field aging [6, 13-19].

Rolt [20] have investigated the effect of field aging on asphalt mixture properties. Based on the results of the study, it was concluded that, the influences of exposure time and temperature had a substantial effect on the characteristics of mixture aging, while the influence of pavement thickness, pavement density and bitumen content were negligible. In a study by Rondón et al. [21], hot mix asphalt was exposed to environmental impacts in Bogota, Colombia for 42 months. The test results showed that, the increase in mixture stiffness, rutting resistance and fatigue resistance was observed in the first 29 months of environmental exposure and the opposite situation was observed between 30 and 42 months. In a study performed by Houston et al. [22], it was observed that, pavement service temperature and pavement air void content significantly affected the aging mixture in the field and aging increased with warmer service temperatures and higher air void contents in the mixture.
In a study by Aschenbrener and Far [23], reheating was found as a significant effect on the aging of asphalt mixtures. They recommended laboratory-produced samples should be conditioned for 2 hours at field compaction temperature to simulate asphalt aging and absorption during plant production.

Bell et al. [9] evaluated the relation between field aging and laboratory aging in terms of short term oven aging (STOA) and long term oven aging (LTOA) protocols. The results from the resilient stiffness modulus indicated that, aging of loose mixtures for 4 hours at $135^{\circ} \mathrm{C}$ represents a short-term aging whereas aging of compacted samples for 120 hours at $85^{\circ} \mathrm{C}$ represents long term aging.

AASHTO R 30 is the current standard recommended by the American Association of State Highway and Transportation Officials (AASHTO) [24] in order to simulate short and long term aging of asphalt mixtures at laboratory. According to that standard, loose mixture specimens should be conditioned for $4 \mathrm{~h}$ at $135^{\circ} \mathrm{C}$ in order to simulate short term aging effects, while, for long term aging simulation, the samples should be compacted with Marshall compactor first and then compacted specimens should be conditioned for 120 hours at $85^{\circ} \mathrm{C}$ to represent long term aging.

Sirin et al. [25] investigated the viscoelastic behavior of the asphalt mixtures by altering the temperature and the duration of the aging procedures. Based on their findings, aging conditions have a considerable effect on the dynamic modulus of the samples. Also, they depicted that, conditioning at $85^{\circ} \mathrm{C}$ for 5 days, which is recommended in AASHTO R30 method, is not sufficient to simulate field aging in hot climatic region for compacted asphalt mixture specimen.

Bonaquist [26] made experimental studies depending on National Cooperative Highway Research Program (NCHRP) Project 09-43. In order to simulate bitumen absorption and aging during construction, a conditioning time at $T_{c}$ was determined (Compaction Temperature) as 2 hours on the other hand, to represent aging over the service life, a representatively higher temperature and longer aging time, which is not more than 16 hours, were determined for the evaluation of moisture susceptibility and rutting resistance.

Epps Martin et al. [27] carried out NCHRP Project 9-49 involving laboratory conditioning experiments. In view of the difficulty of determining the Tc in the field, 2 hours at $135^{\circ} \mathrm{C}$ was recommended as the standard laboratory conditioning protocol instead of 2 hours at $T_{c}$. For long term aging, a significant effect was observed in the increase of the mixture stiffness due to long-term aging both in the 
field and laboratory. Additionally, it was pronounced that, aging occurs more in summer than winter due to high temperatures. In order to simulate the first summer of field aging, the loose samples should be subjected to short-term aging condition for 2 hours at $135^{\circ} \mathrm{C}$ and after compacting the samples they should be conditioned at $60^{\circ} \mathrm{C}$ for 4 weeks to 8 weeks for long term aging.

The more recently completed NCHRP 09-52 project provided a comprehensive review of the existing AASHTO R30 guidelines in addition to the recommendations of the NCHRP 09-43 and NCHRP 09-49 projects. In the NCHRP 09-52 Project, nine field sites were selected in the US to compare laboratory conditional samples with plant mixed samples. Findings from nine site regions depicted that, long term aging procedure, which proposed by AASHTO is suitable, however, STOA aging protocol of $135^{\circ} \mathrm{C}$ for 2 hours of the loose mixture is recommended instead of 4 hours [28].

Partl et al. [11] conducted a study in accordance with RILEM (The International Union of Laboratories and Experts in Construction Materials 206-ATB) with the aim of reproducing recycling asphalt pavement (RAP) by laboratory aging of loose mixture samples. Asphalt mixtures were produced in a plant and nine different laboratories. Laboratory mixes were firstly aged at $135^{\circ} \mathrm{C}$ for 4 hours. For the long-term aging process, both the plant-produced and the short-term laboratory-produced loose mixtures were conditioned in the oven at $85^{\circ} \mathrm{C}$ for $1,2,5,7$ and 9 days. Results showed that, binding oxidation continued for up to nine days, but oxidation rate decreased with increasing conditioning time. Therefore, 4 hours at $135^{\circ} \mathrm{C}$ as short term aging condition and 9 days at $85^{\circ} \mathrm{C}$ as long term aging condition was recommended to simulate aging process.
Kim et al. [29] made research depending on the NCHRP project 09-54. In order to simulate long term aging of asphalt mixtures, a procedure was developed, calibrated and validated with field mixtures obtained from nine field projects which represent the wide variety of climates found in the United States and Canada. A loose mixture aging at $95^{\circ} \mathrm{C}$ was used as an aging protocol in an oven. Aging durations were determined by location, years of aging and depth. The proposed procedure provides a series of laboratory aging time maps for aging of the field area of 4, 8 and 16 years at depths of $6,20 \mathrm{~mm}$ and $50 \mathrm{~mm}$ below the surface to determine the duration. Generally, a period of 4 years and a depth of $20 \mathrm{~mm}$ is taken into account for calculations.

The aim of this study is to compare the different proposed laboratory aging methods with the samples taken from the field for short and long term aging and to determine whether the current standard for aging is still valid. To represent the most accurate short and long term aging, the recently constructed and 5 years aged samples were taken from the field. ITS test was conducted on the samples both taken from the field and prepared at laboratory to evaluate the aging behavior.

\section{Experimental}

\subsection{Materials}

The base bitumen with a 50/70 penetration grade was obtained from Aliaga/Izmir Oil Terminal of the Turkish Petroleum Refinery Corporation. In order to characterize the properties of the base bitumen, conventional test methods such as: penetration test, softening point test, ductility test, etc., were performed. These tests were conducted in conformity with the relevant test methods that are presented in Table 1.

Table 1 50/70 Bitumen binder properties

\begin{tabular}{lccc}
\hline Test & Result & Spec. Limits & Standard \\
\hline Penetration Test $(0.1 \mathrm{~mm})$ & 65 & $50-70$ & ASTM D5-06/ EN 1426 \\
Softening Point Test $\left({ }^{\circ} \mathrm{C}\right)$ & 51 & $46-54$ & ASTM D36-06/ EN 1427 \\
Viscosity (mPa.s) @ $135^{\circ} \mathrm{C}$ & 0.412 & 3000 mPa.s (max.) & ASTM D4402-06 \\
Viscosity (mPa.s) @ $165^{\circ} \mathrm{C}$ & 0.104 & - & ASTM D4402-06 \\
Ductility @ $25^{\circ} \mathrm{C}, \mathrm{cm}$ & 100 & - & ASTM D113 \\
Specific Gravity & 1.030 & 230 (min.) & ASTM D70 \\
Flash Point & +260 & - & ASTM D92 EN 22592 \\
Penetration Index (PI) & 0.35 & & - \\
Rolling Thin Film Oven Test (RTFOT) & & 0.5 (max) & ASTM D 2787-12 \\
Change of mass (\%) & 0.160 & 50 (min) & - \\
Penetration after RTFOT & 53 & 50 (min.) & ASTM D5 EN 1426 \\
Retained Penetration after RTFOT (\%) & 82 & 48 (min.) & ASTM D36-06/ EN 1427 \\
Softening Point after RTFOT (\%) & 58 & ASTM D36-06/ EN 1427 \\
\hline
\end{tabular}


The field core specimens were taken to evaluate the short and long term aging conditions of the laboratory prepared specimens from the recently constructed wearing course and from the surface of a wearing course with a service life of 5 years. It should be mentioned that, the type of the aggregate, the gradation as well as the type of the bitumen used in the field is the same as in the laboratory aged specimens in order to have an accurate comparisons.

Coarse and fine limestone aggregates were procured from Dere Beton/Izmir quarry. In order to find out the properties of the limestone aggregate used in this study, specific gravity, Los Angeles abrasion resistance, sodium sulfate soundness, fine aggregate angularity and fat and elongated particles tests were conducted. The results are presented in Table 2. Grading of aggregate was chosen in conformity with the Type 1 wearing course of Turkish Specifications. Table 3 presents the final gradation chosen for limestone aggregate.

Table 2 Limestone physical properties

\begin{tabular}{|c|c|c|c|}
\hline Test & Results & Spec. Limits & Test Method \\
\hline \multicolumn{4}{|c|}{ Specific Gravity (Coarse Agg.) } \\
\hline - Bulk & 2.704 & - & \\
\hline $\begin{array}{l}\text { - Saturated surface } \\
\text { dry (SSD) }\end{array}$ & 2.717 & - & ASTM C127-07 \\
\hline - Apparent & 2.739 & - & \\
\hline \multicolumn{4}{|c|}{ Specific Gravity (Fine Agg.) } \\
\hline \multirow{3}{*}{$\begin{array}{l}\text { - Bulk } \\
\text { - SSD } \\
\text { - Apparent }\end{array}$} & 2.691 & - & \multirow{3}{*}{ ASTM C128-07 } \\
\hline & 2.709 & - & \\
\hline & 2.739 & - & \\
\hline $\begin{array}{l}\text { Specific Gravity } \\
\text { (Filler) }\end{array}$ & 2.732 & - & \\
\hline $\begin{array}{l}\text { Los Angeles } \\
\text { Abrasion (\%) }\end{array}$ & 2 & 45 (max.) & ASTM C131 \\
\hline $\begin{array}{l}\text { Flat and Elongated } \\
\text { particles }(\%)\end{array}$ & 7.5 & 10 (max.) & ASTM D4791-10 \\
\hline $\begin{array}{l}\text { Sodium Sulfate } \\
\text { Soundness (\%) }\end{array}$ & 1.47 & 10-20 (max.) & ASTM C88-05 \\
\hline $\begin{array}{l}\text { Fine Aggregate } \\
\text { Angularity (FAA) }\end{array}$ & 47.85 & 40 (min.) & ASTM C1252-06 \\
\hline
\end{tabular}

Table 3 Gradation for limestone aggregate

\begin{tabular}{lcc}
\hline Sieve Size/No. & Gradation $(\%)$ & Spec. limits \\
\hline $19 \mathrm{~mm}$ & 100 & 100 \\
$12.5 \mathrm{~mm}$ & 92 & $88-100$ \\
$9.5 \mathrm{~mm}$ & 73 & $72-90$ \\
No. 4 & 44.2 & $42-52$ \\
No. 10 & 31 & $25-35$ \\
No. 40 & 12 & $10-20$ \\
No. 80 & 8 & $7-14$ \\
No. 200 & 5.3 & $3-8$ \\
\hline
\end{tabular}

\subsection{Test methods}

\subsubsection{Marshall Mix Design}

The Marshall Stability method was used to find out the optimum bitumen content for gradation specified in Table 3, in accordance with ASTM D 1559 [30]. Series of test specimens are prepared for a range of different bitumen content so that the test data curves (stability, flow, air void level, bulk specific gravity, voids in mineral aggregate (VMA), voids filled with asphalt (VFA) versus bitumen content) show a well defined optimum value. Consequently, the optimum bitumen content is determined by the bitumen content corresponding to the median of designed limits of percent air voids in the total mix (i.e. $4 \%$ ).

\subsubsection{Aging procedures}

In order to simulate the aging of asphalt in laboratory, the samples were divided into three groups: unaged samples, short term aged samples and long term aged samples. The unaged process does not involve neither short nor long term aging processes. The name of the methods, the conditions (duration and temperature level) of short and long term aging processes are presented in Table 4. It should be noted that, the long term oven aging procedures also involves the short term forced draft oven aging treatment.

As indicated before, AASHTO R30 involves short term forced draft oven aging of loose mixture at $135^{\circ} \mathrm{C}$ for 4 hours and long term aging of compacted samples at $85^{\circ} \mathrm{C}$ for 120 hours. NCHRP 9-52 method involves short term

Table 4 Aging methods

\begin{tabular}{|c|c|c|c|c|c|c|}
\hline \multirow{3}{*}{ Method } & \multicolumn{6}{|c|}{ Aging } \\
\hline & \multicolumn{3}{|c|}{ Short term aging } & \multicolumn{3}{|c|}{ Long term aging } \\
\hline & Temperature $\left({ }^{\circ} \mathrm{C}\right)$ & Duration (hrs) & Mixture type & Temperature $\left({ }^{\circ} \mathrm{C}\right)$ & Duration (Days) & Mixture type \\
\hline AASHTO R30 & \multirow{4}{*}{135} & 4 & Loose & 85 & 5 & Compacted \\
\hline NCHRP 09-54 & & 4 & Loose & 95 & $4^{*}$ & Loose \\
\hline NCHRP 09-52 & & 2 & Loose & 85 & 5 & Compacted \\
\hline RILEM & & 4 & Loose & 85 & 9 & Loose \\
\hline
\end{tabular}

*value determined by calculations 
forced draft oven conditioning of loose mixture at $135^{\circ} \mathrm{C}$ for 2 hours and long term aging of compacted samples at $85^{\circ} \mathrm{C}$ for 120 hours. RILEM method involves short term conditioning of loose mixture at $135^{\circ} \mathrm{C}$ for 4 hours and long term aging of loose mixture at $85^{\circ} \mathrm{C}$ for 216 hours. Regarding NCHRP 09-54 method, the same short-term conditioning was applied as in AASHTO R30 (4 hours at $135^{\circ} \mathrm{C}$ ). For long term aging, a loose mixture aging at $95^{\circ} \mathrm{C}$ was used as an aging temperature. The aging was made using a forced draft oven. The picture of the core samples taken from field is given in Fig. 2, while samples produced at laboratory condition are given in Fig. 3 as loose mix and compacted samples.

The duration of aging were determined by the following equation (Eq. (1)):

$t_{\text {oven }}=\sum_{i=1}^{N} D \cdot A \cdot \exp (-E a /(R \cdot T i)) / 24$,

where:

$t_{\text {oven }}$ required oven aging duration at $95^{\circ} \mathrm{C}$ to reflect field aging (days),

$D$ depth correction factor,

$A$ frequency factor,

$E a$ activation energy,

$R \quad$ universal gas constant (this value is taken as 0.0831 $\mathrm{kJ} / \mathrm{mol} . \mathrm{k}$ ),

$\mathrm{Ti}$ pavement temperature at the depth of interest at the hour of interest (Kelvin).

In this study the depth correction factor $(D)$, the frequency factor $(A)$ and activation energy $(E a)$ is obtained corresponding to pavement layer of $20 \mathrm{~mm}$ depth from the Table 5 .

The pavement temperature ( $T i$ ) was determined by following equation (Eq. (2)) developed by Witczak [31]:

$T i=T a \cdot[1+1 /(z+4)]-34 /(\mathrm{z}+4)+6$,

where:

$\mathrm{Ti}$ hourly pavement temperature $\left({ }^{\circ} \mathrm{F}\right)$,

$\mathrm{Ta}$ hourly air temperature $\left({ }^{\circ} \mathrm{F}\right)$,

$z \quad$ depth below the pavement surface (this value is taken as 0.79 inch corresponding to $20 \mathrm{~mm}$ depth).

For the calculation of $T i$, the 4 main districts (Dikili, Aliaga, Menemen, Buca) of Izmir City was taken into account and the hourly air temperature values $(\mathrm{Ta})$ were taken from the General Directorate of Meteorology for the years of 2015, 2016, 2017 and 2018. The 4 year period is based on the recommendation of the NCHRP 09-54 Method.

$t_{\text {oven }}$ values were then calculated yearly for each district as presented in Table 6 which indicates that, average duration of 4 days should be utilized regarding the simulation of long term aging process.

\subsubsection{Indirect tensile strength test (ITS)}

ITS test was performed in order to evaluate the short and long term aging condition of the laboratory prepared samples. The test is one of the most popular tests used for evaluation of the aging characteristics of asphalt mixtures, which directly affect the performance of the asphalt pavements. ITS test is often used in civil engineering because of its simplicity. The ITS results give information about the laboratory mix design test and allow to predict resistance to failures, such as; cracking and rutting [32].

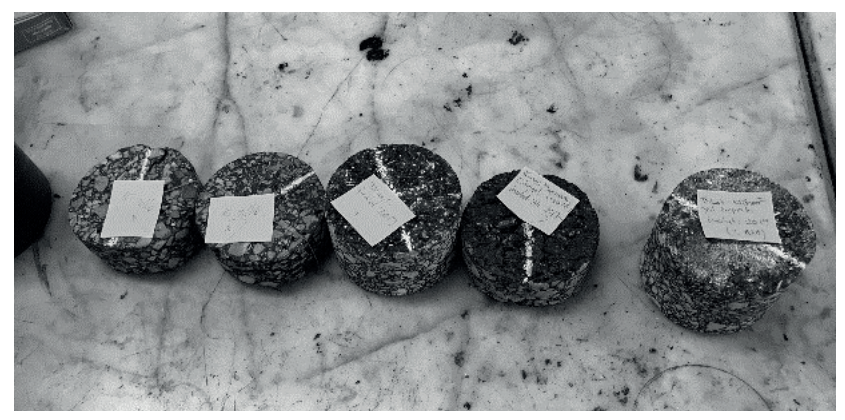

Fig. 2 Core samples taken from field

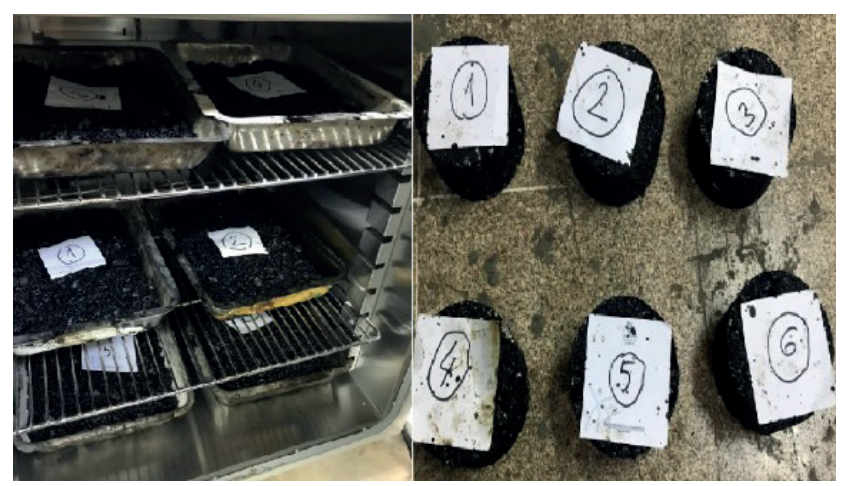

Fig. 3 Laboratory produced loose and compacted samples

Table 5 Climatic aging index coefficients [29]

\begin{tabular}{lccc}
\hline Pavement layer & $\begin{array}{c}\text { Depth correction } \\
\text { factor (D) }\end{array}$ & $\begin{array}{c}\text { Pre-exponential } \\
\text { factor (A) }\end{array}$ & $\begin{array}{c}\text { Activation } \\
\text { energy (Ea) }\end{array}$ \\
\hline $\begin{array}{l}\text { Surface Layer } \\
(6 \mathrm{~mm})\end{array}$ & 1.0000 & 1.40962 & 13.3121 \\
$\begin{array}{l}\text { 20- mm Depth } \\
\text { Deeper Layers } \\
\text { (below } 20 \mathrm{~mm})\end{array}$ & 0.4565 & 1.40962 & 13.3121 \\
\hline
\end{tabular}

Table 6 The Toven values for 4 main districts

\begin{tabular}{lccccc}
\hline $\begin{array}{l}\text { District/ } \\
\text { Years }\end{array}$ & $\begin{array}{c}2015 \\
\text { (days) }\end{array}$ & $\begin{array}{c}2016 \\
\text { (days) }\end{array}$ & $\begin{array}{c}2017 \\
\text { (days) }\end{array}$ & $\begin{array}{c}2018 \\
\text { (days) }\end{array}$ & $\begin{array}{c}\text { Total } \\
\text { (days) }\end{array}$ \\
\hline Dikili & 1.035 & 1.043 & 1.037 & 1.057 & 4.17 \\
Aliaga & 1.039 & 1.052 & 1.039 & 1.062 & 4.19 \\
Menemen & 1.039 & 1.052 & 1.039 & 1.063 & 4.19 \\
Buca & 1.038 & 1.052 & 1.040 & 1.061 & 4.19 \\
\hline
\end{tabular}


The same test was also applied on the field core samples taken from the recently constructed wearing course as well as from the pavement surface with a service life of 5 years. In order to make definite evaluations, the type of the aggregate, the gradation as well as the type of the bitumen used in the field was chosen the same as in the laboratory aged specimens.

The ITS testing is conducted on laboratory aged and field taken samples depending on ASTM D 6931 [33]. Based on this standard, each sample is put in a plastic bag and placed into water for 2 hours at $25^{\circ} \mathrm{C}$ as conditioning. The air should be soaked by a pipette before this procedure. Following, the cylindrical laboratory prepared asphalt samples and the field core samples were correctly placed on the loading frame. The load was applied (at loading rate of $51 \mathrm{~mm} / \mathrm{min}$ )in the vertical diametrical plane and creates a tensile load in the horizontal direction of the sample. The maximum load was read and saved on the device as outlined in.

In order to compute the ITS, the following equation (Eq. (3)) is used:

$S t=\left(2000 x P_{\max }\right) / \pi t D$,

where;

St indirect tensile strength (ITS), $\mathrm{kPa}$

$P$ maximum load, $\mathrm{N}$

$t$ specimen height immediately before test, $\mathrm{mm}$

D specimen diameter, $\mathrm{mm}$

Aging indices were defined to evaluate the aging effects of laboratory prepared asphalt mixtures. The ratio between the ITS values of short and long-term aged samples and the ITS values of unaged samples was calculated as short-term aging index (SAI) and long-term aging index (LAI) (Eqs . (4)-(5)).

$S A I=\frac{(\text { ITS value of short term aged specimens })}{(\text { ITS value of unaged specimens })}$

$L A I=\frac{(\text { ITS value of long term aged specimens })}{(\text { ITS value of unaged specimens })}$

\section{Results and discussions}

\subsection{Marshall Mix Design results}

The Marshall Stability test was conducted on the samples, that contain different bitumen content in order to determine the optimum bitumen content in accordance with ASTM D1559 [31]. In the experimental study, the optimum bitumen content corresponding to $4 \%$ air void (depending on the maximum and minimum air void level presented in the General Directorate of Highways Specifications) was selected as $4.60 \%$ (by weight of aggregate). Test results are presented in Table 7. As indicated in Table 7, all parameters (stability, flow, VFA, VMA) corresponding to $4 \%$ air void level are within the specification limitsThe influence indication of nanomaterials on basic properties of 50/70 asphalt binder is tabulated in Table 7 .

\subsection{Indirect tensile strength test results}

\subsubsection{Results of laboratory aged specimens}

For all the investigated aging methods, it was observed that, the indirect tensile stress (ITS) values of the samples increased from unaged condition to long term aged condition as illustrated in Fig. 4. The increase in indirect tensile stress values is considered as an indicator of the effect of aging.

Among the all short term aged specimens subjected to investigated methods, the short term aged sample by the method of NCHRP 09-52 yielded the minimum (although the variation is not significant) ITS values since the NCHRP 9-52 method involves 2 hours of oven aging of loose samples. The short term aged samples produced by other methods demonstrated similar ITS values.

In case of long term aged specimens, the long term aged sample by RILEM Method yielded the highest ITS value indicating pronounced effect of aging. As expected, long term aged specimens by traditional method (AASHTO R30) and NCHRP 09-52 yielded similar ITS values.

Table 7 Marshall Mix Design test results

\begin{tabular}{lcc}
\hline Parameter & Result & Specification for wearing course \\
\hline $\begin{array}{l}\text { Optimum bitumen } \\
\text { content (\%) }\end{array}$ & 4.8 & $4-7$ \\
Stability (kg) & 1135 & $900(\mathrm{~min})$ \\
Flow (mm) & 2.60 & $2-4$ \\
VFA (\%) & 71 & $65-75$ \\
VMA (\%) & 14 & $14-16$ \\
\hline
\end{tabular}

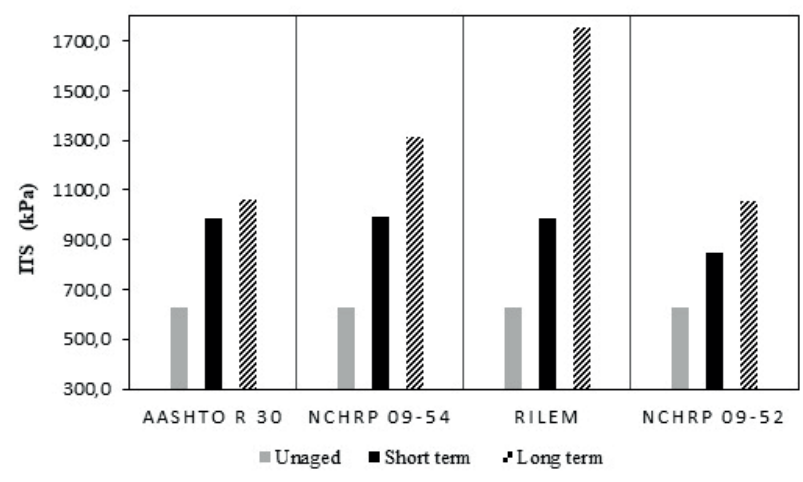

Fig. 4 ITS results of aging method 
Short term aging (SAI) and long term aging indices (LAI) were calculated for the evaluation of aging characteristics of the samples. Fig. 5 represents the indices corresponding to each method.

Based on Fig. 5, it can be said that, the lower the aging index values, the less aging effect the bituminous mixture exposes. Among the short term aged samples, the short term aged sample by NCHRP 09-52 method yielded less aging indices. The short term indices regarding AASHTO R30, NCHRP 09-54 and RILEM Method yielded similar aging index values. Long term aging index values indicates that, RILEM Method produced higher long term index values. Besides, NCHRP 09-52 and traditional method yielded similar long term index values.

\subsubsection{Results of field core specimens}

The ITS values of both field core samples and the laboratory aged specimens are presented in Fig. 6 .

As indicated in Fig. 6, the ITS value regarding to sample taken from the 5 years old pavement surface is higher than the asphalt core taken from the recently constructed pavement surface. As expressed before, the increment in the ITS value is an indicator to effect of aging. When comparing the specimen taken from the recently constructed pavement with the laboratory short term aged specimens

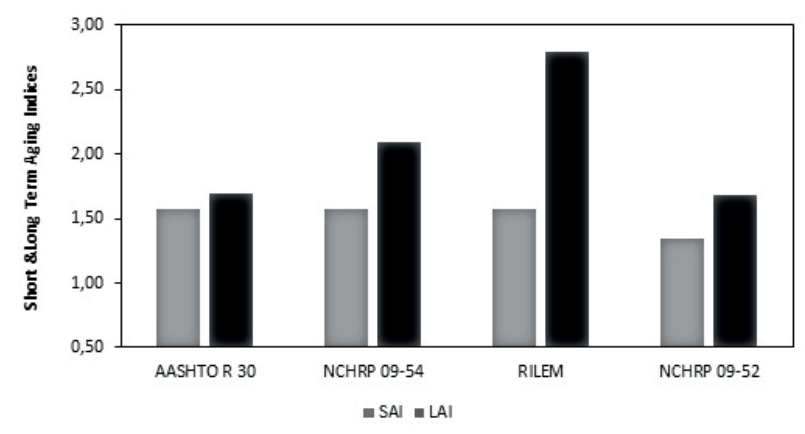

Fig. 5 Short and long term aging index results of all methods

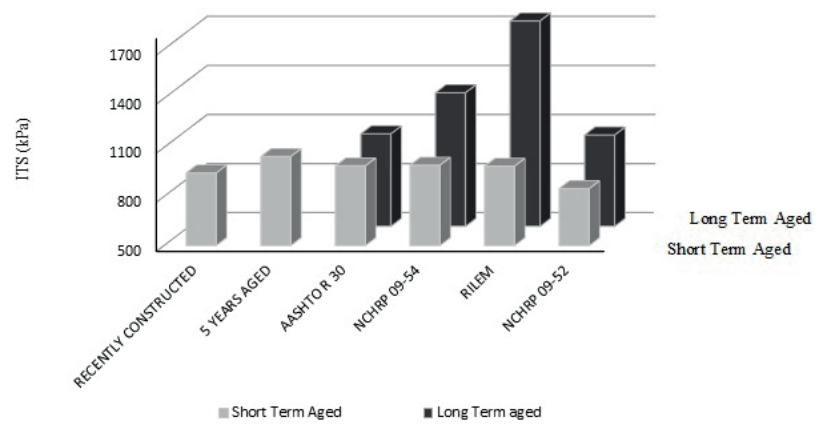

Fig. 6 ITS results of field core specimens (simulating the aging process during mixing with aggregate, laying and compaction), the ITS value of sample short term aged specimen by AASHTO R30, NCHRP 09-54 and RILEM Method has demonstrated similar values with the ITS value of recently constructed sample.

When comparing the ITS values of the long term laboratory oven aged specimens with 5 years old field specimen, the ITS value of long term aged specimen by AASHTO R30, NCHRP 09-52 and yielded similar values with the ITS value of sample taken from 5 years aged pavement surface.

\section{Conclusions and recommendations}

This study is aimed to evaluate the aging procedures of hot mix asphalt with current standard (AASHTO R30) as well as alternative methods (NCHRP 09-52, NCHRP 09-54 and RILEM) by way of indirect tensile strength test. The level of aging has been also compared with the samples taken from recently constructed pavement surface and from the 5 years old pavement surface.

The following conclusions can be withdrawn from this study:

- For all the investigated aging methods, the indirect tensile stress values of the samples increased from unaged condition to long term forced draft oven aged conditions.

- Among the all short term forced draft oven aged samples, all of the investigated methods yielded similar ITS values due to the fact that, all the short term oven aging conditions regarding each method do not exhibit significant difference.

- It may be concluded that 2 hours or 4 hours short term forced draft oven aging of loose samples at $135^{\circ} \mathrm{C}$ does not yield significant variation in the ITS values of long term aged samples. Therefore, the 2 hours forced draft oven aging at $135^{\circ} \mathrm{C}$ can be recommended as short term aging condition.

- Considering the findings from the short and long term aging indices, which were calculated for the evaluation of aging characteristics of the samples, it is possible to consider that, lower aging index values exhibit less effect of aging.

- A significant variation is observed between the ITS values of long term laboratory aged specimens and 5 years old field core samples, when NCHRP 09-54 method is used. Therefore, AASHTO R30 and NCHRP 09-52 methods are recommended as long term aging methods. 
This study covers the utilization of one type of aggregate and 50/70 penetration grade bituminous binder. More research can be made by using different aggregate type as well as bitumen.

\section{References}

[1] Krchma, L. C., Gagle, D. W. "A U.S.A. history of asphalt refined from crude oil and its distribution", Proceedings of Association of Asphalt Paving Technologists, 43A, pp. 25-88, 1974.

[2] Croney, D., Croney, P. "The design and performance of road pavements", 2nd ed., McGraw-Hill, New York, NY, USA, 1991.

[3] Kaya, D., Topal, A., Gupta, J., McNally, T. "Aging effects on the composition and thermal properties of styrene-butadiene-styrene (SBS) modified bitumen", Construction and Building Materials, 235, Article No. 117450, 2020.

https://doi.org/10.1016/j.conbuildmat.2019.117450

[4] Kaya, D., Topal, A., McNally, T. "Correlation of processing parameters and ageing with the phase morphology of styrene-butadiene-styrene block co-polymer modified bitumen", Materials Research Express, 6, Article No. 105309, 2019.

https://doi.org/10.1088/2053-1591/ab349c

[5] Kaya, D., Topal, A., McNally, T. "Relationship between processing parameters and aging with the rheological behaviour of SBS modified bitumen", Construction and Building Materials, 221, pp. 345-350, 2019.

https://doi.org/10.1016/j.conbuildmat.2019.06.081

[6] Traxler, R. N. "Relation between Asphalt Composition and Hardening by Volatilization and Oxidation", Proceedings of Association of Asphalt Paving Technologists, 30, pp. 359-377, 1961.

[7] Traxler, R. N. "Durability of Asphalt Cements", Proceedings of Association of Asphalt Paving Technologists, 32, pp. 44-63, 1963.

[8] Petersen, J. C. "Chemical Composition of Asphalt as Related to Asphalt Durability: State of the Art", Transportation Research Record, 999, pp. 13-30, 1984. [online] Available at: http://onlinepubs.trb.org/Onlinepubs/trr/1984/999/999-004.pdf [Accessed: 24 December 2019]

[9] Bell, C. A., Wieder, A. J., Fellin, M. J. "Laboratory Aging of AsphaltAggregate Mixtures: Field Validation", Strategic Highway Research Program, National Research Council, Washington, DC, USA, Rep. SHRP A-390, 1994. [online] Available at: http://onlinepubs.trb.org/ onlinepubs/shrp/SHRP-A-390.pdf [Accessed: 24 December 2019]

[10] Hunter, R. N., Self, A., Read, J. "The Shell Bitumen Handbook", 6th ed., ICE Publishing, London, UK, 2015.

https://doi.org/10.1680/tsbh.58378

[11] Partl, M. N., Bahia, H. U., Canestrari, F., de la Roche, C., Di Benedetto, H., Piber, H., Sybilski, D. (eds.) "Advances in Interlaboratory Testing and Evaluation of Bituminous Materials", Springer, Dordrecht, Netherlands, 2012. https://doi.org/10.1007/978-94-007-5104-0

[12] Elwardany, M. D., Rad, F. Y., Castorena, C., Kim, Y. R. "Evaluation of asphalt mixture laboratory long-term ageing methods for performance testing and prediction", Road Materials and Pavement Design 18(sup1), pp. 28-61, 2017.

https://doi.org/10.1080/14680629.2016.1266740

\section{Acknowledgement}

The authors are thankful to the Graduate School of Natural and Applied Sciences of Dokuz Eylul University for its support.

[13] Topal, A., Sengoz, B. "Effect of SBS polymer modified bitumen on the ageing properties of asphalt", In: Proceedings of the 4th Eurasphalt and Eurobitume Congress, Copenhagen, Denmark, 2008, pp. 1147-1153.

[14] Morian, N., Hajj, E. Y., Glover, C. J., Sebaaly, P. E. "Oxidative Aging of Asphalt Binders in Hot-Mix Asphalt Mixtures", Transportation Research Record: Journal of the Transportation Research Board, 2207(1), pp. 107-116, 2011. https://doi.org/10.3141/2207-14

[15] Daniel, J. S., Bennert, T., Kim, Y. R., Mogawer, W., Congalton, A., Mensching, D., Sabouri, M., Elwardany, M. "Evaluation of plant produced RAP mixtures in the northeast: Phase I interim report", Federal Highway Administration, Washington, DC, USA, Rep. TPF 5(230), 2014.

[16] Tóth, Cs., Ureczky, J. "Determination of master curves for asphalt mixtures by means of IT-CY tests", Periodica Polytechnica Civil Engineering, 54(2), pp. 137-142, 2010. https://doi.org/10.3311/pp.ci.2010-2.09

[17] Devecseri, G. "Effect of heating on the physical properties of asphalt aggregates", Periodica Polytechnica Civil Engineering, 54(1), pp. 53-60, 2010.

https://doi.org/10.3311/pp.ci.2010-1.06

[18] Bocz, P. "The effect of stiffness and duration parameters to the service life of the pavement structure", Periodica Polytechnica Civil Engineering, 53(1), pp. 35-41, 2009. https://doi.org/10.3311/pp.ci.2009-1.05

[19] Chen, C., Yin, F., Turner, P., West, R. C., Tran, N. "Selecting a Laboratory Loose Mix Aging Protocol for the NCAT Top-Down Cracking Experiment", Transportation Research Record: Journal of the Transportation Research Board, 2672(28), pp. 359-371, 2018. https://doi.org/10.1177/0361198118790639

[20] Rolt, J. "Top-down cracking: myth or reality", In: The World Bank Regional Seminar on Innovative Road rehabilitation and recycling technologies, Amman, Jordan, 2000, pp. 24-26.

[21] Rondón, H. A., Reyes, F. A., Flintsch, G. W., Mogrovejo, D. E. "Environmental Effects on Hot Mix Asphalt Dynamic Mechanical Properties: - A Case Study in Bogota, Colombia", presented at Transportation Research Board 91st Annual Meeting, Washington, DC, USA, Jan. 22-26, 2012. [online] Available at: https://www. researchgate.net/publication/279861010_Environmental_Effects on_Hot-Mix_Asphalt_Dynamic_Mechanical_Properties_Case Study_in_Bogota_Colombia [Accessed: 24 December 2019]

[22] Houston, W. N., Mirza, M. W., Zapata, C. E., Raghavendra, S. "Environmental Effects in Pavement Mix and Structural Design Systems", National Cooperative Highway Research Program, Washington, DC, USA, NCHRP Web-Only Doc. 113, 2005. https://doi.org/10.17226/23244 
[23] Aschenbrener, T., Far, N. "Short-Term Aging of Hot Mix Asphalt", Colorado Department of Transportation Public, Denver, CO, USA, Rep. CDOT-DTD-R-94-11, 1994. [online] Available at: https:// www.codot.gov/programs/research/pdfs/1994-research-reports/ shorttermaging.pdf/view [Accessed: 24 December 2019]

[24] American Association of State Highway and Transportation Officials "Standard practice for mixture conditioning of hot mix asphalt (HMA) AASHTO R30", AASHTO, Washington, DC, USA, 2002.

[25] Sirin, O., Ohiduzzaman, M., Kassem, E., Paul, D. K. "Comprehensive evaluation of long-term aging of asphalt mixtures in hot climatic condition", Road Materials and Pavement Design, 21(4), pp. 927-949, 2020

https://doi.org/10.1080/14680629.2018.1531777

[26] Bonaquist, R. "Mix Design Practices for Warm Mix Asphalt", Transportation Research Board, Washington, DC, USA, Rep. NCHRP 691, 2011.

https://doi.org/10.17226/14488

[27] Epps Martin, A., Arambula, E., Yin, F., Cucalon, L. G., Chowdhury, A., Lytton, R., Epps, J., Estakhri, C., Park, E. S. "Evaluation of the Moisture Susceptibility of WMA Technologies", Transportation Research Board, Washington, DC, USA, Rep. NCHRP 763, 2014. https://doi.org/10.17226/22429

[28] Newcomb, D., Epps Martin, A., Yin, F., Arambula, E., Park, E. S., ..., Signore, J. M. "Short-Term Laboratory Conditioning of Asphalt Mixtures", Transportation Research Board, Washington, DC, Rep. NCHRP 815, 2018.

https://doi.org/10.17226/22077
[29] Kim, Y. R., Castorena, C., Elwardany, M., Rad, F. Y., Underwood, S., Gundla, A., Gudipudi, P., Farrar, M. J., Glaser, R. R. "Long-Term Aging of Asphalt Mixtures for Performance Testing and Prediction", Transportation Research Board, Washington, DC, Rep. NCHRP 871, 2018.

https://doi.org/10.17226/24959

[30] ASTM "ASTM D1559 Standard Test Method for Marshall Test, Annual Book of ASTM Standards", ASTM International, West Conshohocken, PA, USA, 2002.

[31] Witczak, M. W. "Design of full-depth asphalt airfield pavements", In: The Third International Conference on the Structural Design of Asphalt Pavements, Grosvenor House, Park Lane, London, England, 1972, pp. 550-567.

[32] Srinivasan, G. "Evaluation of Indirect Tensile Strength to Identify Asphalt Concrete Rutting Potential", MSc Thesis, West Virginia University, 2004.

https://doi.org/10.33915/etd.1465

[33] ASTM "ASTM D6931-12 Standard Test Method for Indirect Tensile (IDT) Strength of Bituminous Mixtures", ASTM International, West Conshohocken, PA, USA, 2012.

https://doi.org/10.1520/D6931-12 